\title{
The Diagnostic Peritoneal Lavage: A Brief Review of the Current Literature and an Analysis of Its use and Teaching in Canada
}

\author{
Darrell Boone, Colin A Clarkson
}

\begin{abstract}
Introduction: The vast majority of the published data on the appropriate use of the diagnostic peritoneal lavage (DPL) is dated. Currently in Canada, there is a significant grey-zone surrounding the teaching and use of the DPL. The objectives of this article are to briefly review the recent literature, to analyze the patterns in the use of the DPL in Canada, and to determine whether general surgery residents are being taught the skill.
\end{abstract}

Methods: Literature review was conducted using PubMed and Ovid. The Canadian Institute for Health Information (CIHI) supplied the available data on DPL usage in Canada. General surgery program directors in Canada were contacted by e-mail to determine if the DPL was still being taught.

Results: Between the years of 2001 and 2006 in Canada, 38 DPLs were coded into the CIHI's database. Males accounted for $84.2 \%$ of the DPLs, and $23.7 \%$ of all DPLs resulted in a laparotomy. Motor vehicle crashes were the reason that $42 \%$ of the DPLs were performed. The majority of general surgery residency programs in Canada are not teaching the DPL outside of what is taught in the advanced trauma life support (ATLS) course.

Discussion: The literature reviewed shows that the DPL continues to play a role in the current management of patients suffering from both blunt and penetrating trauma, although a much more limited role than in the past.

Keywords: Diagnostic peritoneal lavage (DPL), DPL use in Canada.

How to cite this article: Boone D, Clarkson CA. The Diagnostic Peritoneal Lavage: A Brief Review of the Current Literature and an Analysis of Its use and Teaching in Canada. Panam J Trauma Critical Care Emerg Surg 2012;1(3):150-153.

Source of support: Nil

Conflict of interest: None declared

\section{RESUMEN}

Introducción: La majoria de los articulos publicados acerca del uso apropriado del DPL (Diagnostic Peritoneal Lavage) son viejos. En este momento en Canada, hay una significante zona gris rodeando la ensenanza y el uso del DPL. Los objectivos de este articulo son para dar una breve revision de los articulos recientes, analizar los modelos en el uso del DPL en Canada, y determinar si los residentes de cirugia general estab siendo ensenados en el uso del DPL.

Métodos: Un revision de la literatura fue llevado a cabo usando PubMEd y Ovid. El Instituto Canadiense para la Informacion de la Salud (CIHI-Canadian Institute for Health Information) suplio los datos acerca del uso del DPL en Canada. Los directores de los programas de cirugia general en Canada estaban contactado por email para saber si estaban ensenando el uso del DPL todavia.
Resultados: Entre los anos 2001 y 2006 en Canada, 38 DPL's fueron codificados en la base de datos del CIHI. $84.2 \%$ eran hombres, y $23.7 \%$ de todos DPL's resultaron en una laparotomia. $42 \%$ fueron realizados como resultado de accidentes de carro. La mayoria de los programas de cirugia general en Canada no estan ensenando el uso del DPL fuera de lo que es ensenado en el ATLS curso.

Discusión: La revision de la literatura muestra que el DPL continua jugando un papel todavia tiene un papel en el manejo de los pacientes traumatizados, pero mucho menos que en el pasado.

Palabras claves: Lavado peritoneal diagnostico (LPD), El uso del LPD en Canada.

\section{INTRODUCTION}

At present in Canada, there appears to be a significant greyzone surrounding the teaching and use of the diagnostic peritoneal lavage (DPL), which was first described in 1965 . $^{1}$ This inconsistency in Canada most likely reflects inconsistency on an international level. Many surgeons have stated that the DPL has been largely supplanted by computed tomography (CT) or focused abdominal sonography for trauma (FAST).

The vast majority of published data on the appropriate use of the DPL is dated. A review article published in 2009 demonstrates the paucity of recent literature on DPLs. Of all articles cited which in any way relate to the role of the DPL, it includes five published after 1990, only three of which were published after the year $2000 .^{2}$ During this same time period, significant advances have been made in the technology of CT scans and FAST.

The objectives of this article are to briefly review the recent literature on the appropriate use of the DPL, to analyze the patterns in use of the DPL in Canada, and to determine whether Canadian general surgery residents are being taught the skill.

\section{METHODS}

A literature search was carried out using PubMed and Ovid, with diagnostic peritoneal lavage and DPL as search terms. Data was restricted to the years 2000 and on. The date of the literature search was May 2009, therefor, only publications to this date were included. Bibliographies of all relevant articles obtained in the literature search were used to locate additional important articles, and these were also collected for review. 
In order to determine the patterns of DPL usage in Canada, we requested that the Canadian Institute for Health Information (CIHI) supply the available data using the National Trauma Registry's MDS (minimum data set). The CIHI maintains large databases with coded information input from the various trauma registries and hospital databases across Canada. All Canadian hospitals, both trauma and non-trauma centers, must submit to CIHI.

In an attempt to determine if general surgery residents in Canada were being taught how to perform the DPL, program directors of English speaking general surgery residency programs across Canada were contacted via the e-mail addresses listed in the CaRMS (Canadian Resident Matching Service) website. All were asked the following question: Is the DPL (diagnostic peritoneal lavage) taught to the residents in your program, besides what is taught in the ATLS ${ }^{\text {TM }}$ (Advanced Trauma Life Support) course?

In order to try and judge the accuracy of the CIHI coding of DPLs we also asked the following question of all program directors: To the best of your knowledge, how many DPLs for trauma have been performed within your hospital system since 2001 (this was the first year the CIHI had began coding DPLs into their database).

\section{RESULTS}

\section{Review}

The few articles which have been published in the recent literature continue to demonstrate controversy in the exact role of the DPL in trauma. In the hemodynamically stable patient with stab wounds and no other reason for surgery, several authors have recently published articles supporting the use of the DPL following local wound exploration (LWE) as a way of determining the need for laparotomy. ${ }^{2-5}$ These are not, however, standards in keeping with the recently published guidelines of either the eastern (EAST) or western (WEST) trauma associations. ${ }^{6,7}$ It should be noted that one of the aforementioned articles which recently supported the use of LWE followed by DPL concluded by stating that the authors had in fact recently changed their own practice away from the LWE followed by DPL to LWE followed by serial clinical exams, in keeping with the recently published WEST guidelines. ${ }^{5}$ Another set of authors recently concluded that using the DPL on hemodynamically stable patients with abdominal stab wounds and no other reason for surgery is appropriate care, without the use of LWE first. ${ }^{8}$

In blunt trauma, the DPL remains of use in various settings. When CT and FAST are not available, the DPL can be used in a hemodynamically stable patient suffering from blunt trauma in whom intra-abdominal injury is suspected. ${ }^{2}$
The DPL may also play a role when CT is available and shows a questionable bowel injury, ${ }^{3}$ particularly in light of a recently published article showing that newer CT technology continues to miss blunt bowel and mesenteric injuries. ${ }^{9}$ In the hemodynamically unstable blunt trauma patient, DPL can be used if there is no FAST available or if the FAST is equivocal. ${ }^{2,3}$

The DPL can be performed in several different ways, with a recent review indicating that complication rates are similar with all techniques. ${ }^{2}$ The open technique utilizes a vertical incision and direct visualization of peritoneal entry, while the closed technique relies on percutaneous needle access to the peritoneal cavity, followed by the insertion of a catheter using Seldinger technique. ${ }^{2}$ The semi-open technique follows the same principles of the open technique except that the midline fascia is penetrated with a needle and the catheter is advanced using the Seldinger technique. ${ }^{2}$

Different authors have used different criteria to classify a DPL as positive. Examples of a grossly positive DPL include aspiration of enteric contents or $10 \mathrm{ml}$ or more of blood. ${ }^{2,5}$ Biochemically positive DPLs may include those with $>500$ / $\mathrm{mm}^{3}$ white blood cells (WBC), $>100,000 / \mathrm{mm}^{3}$ red blood cells (RBC) as well as varying levels of amylase, alkaline phosphate and bilirubin. ${ }^{2,5,10}$ Several authors advocate a lower threshold for the RBC's and some use differing levels depending on the specific mechanism of injury. ${ }^{4,11}$

Complications are very rare following a DPL, if proper principles are adhered to, such as first decompressing the stomach and urinary bladder. ${ }^{2,11}$ Complications, such as wound problems, small bowel/mesenteric injuries, bladder punctures and abdominal wall infusions are reported in approximately one percent of patients. ${ }^{2,11}$

\section{Canadian Data}

The DPL was not being coded into the MDS until the year 2001 , at which time select provinces and territories began coding for it. By 2003, all provinces and territories were coding for the DPL, with the exception of New Brunswick and Manitoba. New Brunswick and Manitoba were coding for the DPL by 2004 and 2005 respectively.

Privacy policies within the CIHI prevent the release of detailed information regarding small data sets. The $\mathrm{CIHI}$ was able to supply limited data on DPLs performed in Canada from 2001 to 2006.

Between the years 2001 and 2006 in Canada, 38 DPLs were coded into the CIHIs database. A breakdown of numbers performed by year is shown in Table 1. Of the 38 DPLs coded into the MDS, $39.5 \%$ were performed in British Columbia, $31.6 \%$ were performed in Ontario, and the remaining 28.9\% 
were performed in Alberta, New Brunswick, Nova Scotia, Newfoundland, and the Yukon Territory. Males accounted for $84.2 \%$ of the DPLs and $23.7 \%$ of all DPLs resulted in a laparotomy. A breakdown of DPLs by age category is shown in Table 2. Motor vehicle crashes were the reason that $42 \%$ of the DPLs were performed. The remaining $58 \%$ were performed for a variety of reasons, but CIHI privacy policies did not allow a more precise breakdown due to the relatively small numbers performed.

\begin{tabular}{|c|c|c|}
\hline Fiscal year & Frequency & Percentage \\
\hline $2001-2002$ & 5 & 13.2 \\
\hline $2002-2003$ & 13 & 34.2 \\
\hline $2003-2004$ & 5 & 13.2 \\
\hline $2004-2005$ & 10 & 26.3 \\
\hline $2005-2006$ & 5 & 13.2 \\
\hline
\end{tabular}

The CaRMS website lists a total of 14 English speaking general surgery programs in Canada, and e-mail contact was attempted with all program directors. Responses were received from seven of them (50\%). Only two out of seven (29\%) teach the DPL outside of the ATLS ${ }^{\mathrm{TM}}$ course. Estimates regarding the number of DPLs performed at each institution ranged from zero to four per year.

\begin{tabular}{|c|c|c|}
\hline \multicolumn{3}{|c|}{$\begin{array}{l}\text { Table 2: A breakdown of DPLs performed in } \\
\text { Canada by age group }\end{array}$} \\
\hline Age group & Frequency & Percentage \\
\hline $0-19$ & 8 & 21.1 \\
\hline $20-29$ & 7 & 18.4 \\
\hline $30-29$ & 7 & 18.4 \\
\hline $40-49$ & 6 & 15.8 \\
\hline $50+$ & 10 & 26.3 \\
\hline
\end{tabular}

\section{DISCUSSION}

This article has several shortcomings. The limitations placed by the CIHI privacy policies make it impossible to analyze the data any more specifically. The fact that not all provinces and territories began coding for the DPL in the same year also makes it difficult to draw conclusion about trends in DPL usage.

There is little data in the literature addressing the accuracy of the CIHI databases, and no article was located which addressed trauma or the MDS specifically. One study in Ontario looking at CIHI coding in cardiac patients concluded that while myocardial infarction is generally accurately coded in hospital discharge abstract data, other cardiac diagnoses (such as arrhythmia, congestive heart failure, unstable angina and chest pain not yet diagnosed) are less reliably coded. ${ }^{12}$ A second article, again from Ontario, concluded that data from the $\mathrm{CIHI}$ regarding significant bile duct injuries must be interpreted with caution. ${ }^{13}$ In an attempt to try and estimate the accuracy, the CIHI coding of DPLs into the MDS, we asked the surgery program directors for their estimation of the number of DPLs performed in their respective institutions. A rough estimate of DPLs performed over a recent 5-year period, from the information supplied by program directors, is that 30 DPLs were performed at the seven responding institutions. If this estimate were doubled to include the seven non-responding institutions, the total number of DPLs estimated to have been performed in Canada over a recent five year period would be 60 . The CIHI coded 38 DPLs over a similar 5 years period, despite not having all provinces and territories submitting information initially. These numbers cannot be used to definitively support or refute the accuracy of the CIHI coding of DPLs into the MDS. However, both totals are similar when all factors are considered, and both numbers support the conclusion that the DPL continues to be used in trauma care in Canada, although to a limited extent.

The literature reviewed shows that the DPL continues to play a role in modern trauma care, although a much more limited role than in the past. In some centers, the DPL is used as one of several tools in the evaluation of hemodynamically stable patients with penetrating trauma. However, it should be recognized that this usage is still highly debated. In the setting of a hemodynamically stable patient suffering from blunt trauma in whom intra-abdominal injury is suspected, the DPL continues to have a role in the absence of CT or FAST availability. The DPL may also play a role when CT is available and shows a questionable bowel injury. Finally, in the hemodynamically unstable blunt trauma patient, DPL continues to have a role if there is no FAST available or if the FAST is equivocal. Further investigations in the modern trauma setting would help to clarify the exact role of the DPL in patient care, particularly in regards to stable patients suffering from penetrating trauma, and in stable patients suffering from blunt trauma in whom the CT shows a questionable bowel injury. Finally, consensus regarding what constitutes a positive DPL could be better defined.

In keeping with the continued role of the DPL found in the literature, we have demonstrated that the DPL continues to be utilized in Canada in selected cases. However, most Canadian general surgery programs are not teaching residents how to perform a DPL outside of what they are exposed to in an ATLS ${ }^{\mathrm{TM}}$ course. Given the continued usage in Canada and in trauma care in general, we suggest that there should be further training provided to surgery residents in both the technical aspects of the DPL as well as in the appropriate indications for usage in modern trauma care. 


\section{REFERENCES}

1. Root HD, Hauser CW, McKinley CR, et al. Diagnostic peritoneal lavage. Surgery 1965;57:633-37.

2. Whitehouse JS, Weigelt JA. Diagnostic peritoneal lavage: A review of indications, technique, and interpretation. Scandinavian Journal of Trauma, Resuscitation and Emergency Medicine 2009;17(13).

3. Sarin E, Kashuk JL, Cothren CC, et al. Not so fast: Diagnostic peritoneal lavage remains a valuable adjunct to modern imaging techniques (EAST abstract). J Trauma 2007;63:1428.

4. Sriussadaport S, Pak-Art R, Pattaratiwanon M, et al. Clinical uses of diagnostic peritoneal lavage in stab wounds of the anterior abdomen: A prospective study. Eur J Surg 2002;168(8-9):490-93.

5. Cothren CC, Moore EE, Warren FA, et al. Local wound exploration remains a valuable triage tool for the evaluation of anterior abdominal stab wounds. The American Journal of Surgery 2009; in press.

6. Como JJ, Bokhari F, Chui WC, et al. Practice management guidelines for nonoperative management of penetrating abdominal trauma. EAST guidelines 2007. Available from: http://www.east.org/tpg/nonoppene.pdf.

7. Biffl WL, Kaups KL, Cothren CC, et al. Management of patients with anterior abdominal stab wounds: A western trauma association multicenter trial. J of Trauma 2009;66(5):1294-1301.

8. Gonzalez RP, Turk B, Falimirski ME, et al. Abdominal Stab Wounds: Diagnostic peritoneal lavage criteria for emergency room discharge. J Trauma 2001;51:939-43.
9. Ekeh AP, Saxe J, Walusimbi M, et al. Diagnosis of blunt intestinal and mesenteric injury in the era of multidetector CT technology are results better? J Trauma 2008;65(2):354-59.

10. Thacker LK, Parks J, Thal ER. Diagnostic peritoneal lavage: Is 100,000 RBCs a valid figure for penetrating abdominal trauma? J Trauma 2007;62(4):853-57.

11. Nagy KK, Roberts RR, Joseph KT, et al. Experience with over 2500 diagnostic peritoneal lavages. Injury 2000;31:479-82.

12. Austin PC, Daly PA, Tu JV. A multicenter study of the coding accuracy of hospital discharge administrative data for patients admitted to cardiac care units in Ontario. Am Heart J 2002;144:290-96.

13. Taylor B. Common bile duct injury during laparoscopic cholecystectomy in Ontario: Does ICD-9 coding indicate true incidence? CMAJ 1998;158(4):481-85.

\section{ABOUT THE AUTHORS}

\section{Darrell Boone (Corresponding Author)}

Department of Surgery and Critical Care, Memorial University of Newfoundland, St. John's, Newfoundland, Canada, e-mail: dboone@ mun.ca

\section{Colin A Clarkson}

Department of Surgery, Memorial University of Newfoundland St John's, Newfoundland, Canada 